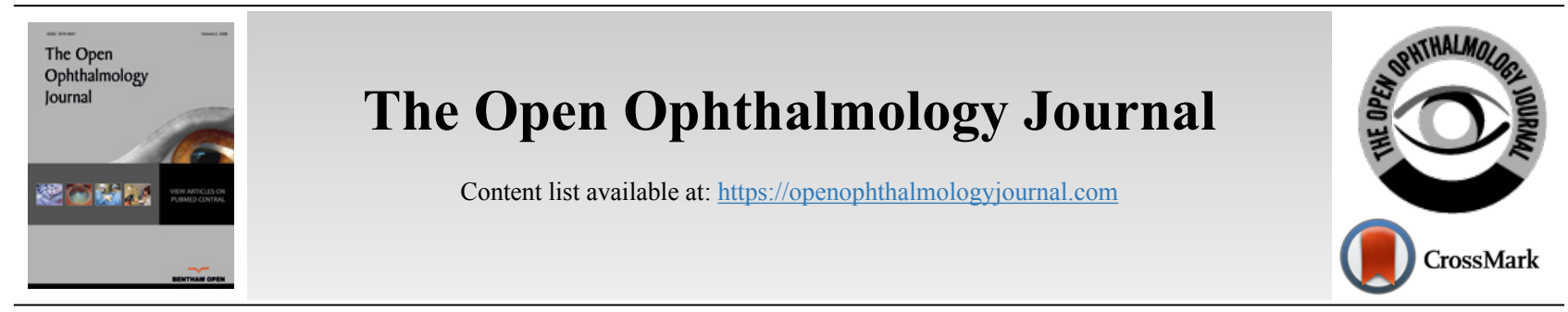

RESEARCH ARTICLE

\title{
Dual Pathogenesis of Primary and Recurrent Pterygium: Immunohistochemical Proof
}

\author{
Doaa Ghorab ${ }^{1}$, Ahmed Helaly ${ }^{2,3, *}$ and Amani Badawi ${ }^{4}$ \\ ${ }^{1}$ Department of Pathology Mansoura University, Mansoura, Egypt \\ ${ }^{2}$ Clinical Science, Yarmouk University, Irbid, Jordan \\ ${ }^{3}$ Department of Forensic Medicine and Clinical Toxicology, Mansoura University, Mansoura, Egypt \\ ${ }^{4}$ Department of Opthalmology Mansoura University, Mansoura, Egypt
}

\begin{abstract}
:
Introduction:

Pterygium is a common ophthalmic problem in the Middle East where exposures to dust and sun rays are risk factors. The condition is more prevalent in middle-aged males and can be considered as an aging process. The aim of this study is to test both the degenerative and the proliferative components of Pterygium by both reduced glutathione and topoisomerase one activity.

Methods:

The study applied immunohistochemistry staining for both reduced glutathione and topoisomerase 1 .

Results:

The samples expressed positive glutathione staining in most primary Pterygium conditions and all secondary Pterygium. On the other hand, the topoisomerase 1 immunohistochemistry expressed focal activity in secondary conditions suggesting a progenitor cell role in the pathogenesis of Pterygium in conjunction with oxidative stress.

Conclusion:

Pterygium represents dual pathology with a proliferative component and a degenerative one that needs further studies. It is possible to use combination immunohistochemistry markers to predict the prognosis of Pterygium behavior.
\end{abstract}

Keywords: Glutathione, Immunohistochemistry, Oxidative stress, Pterygium, Topoisomerase 1, Pathology.

\begin{tabular}{|l|l|l|l}
\hline Article History & Received: April 27, 2021 & Revised: July 15, 2021 & Accepted: July 27, 2021
\end{tabular}

\section{INTRODUCTION}

Pterygium is a possible aging-related condition that is associated with collagen degeneration. This degeneration expressed fibro-vascular reaction creeping over the cornea. The pathogenesis of Pterygium is not clear. However, Sunrays and exposure to dust are risk factors for this condition. A widespread meta-analysis study on more than 400000 candidates worldwide demonstrated increasing rates of Pterygium cases with age predominantly in males exposed to sun rays. The condition was aggravated in rural areas with the highest prevalence in China. Sunglasses and smoking were

\footnotetext{
Address correspondence to this author at Department of Clinical Science, Yarmouk University, Yarmouk, Jordan; Tel: 0790329576;

E-mail: ahmedhelaly@mans.edu.eg
}

considered protective factors against Pterygium pathology [1, 2]. However, it is not explained how smoking improves the condition despite that sun rays and aging share the burden of oxidative stress with smoking.

Scientists proposed a multifactorial theory to explain Pterygium with possible genetic, immunological, and viral infection causes of the development of such pathology. On the other hand, it is important to notice that Pterygium has a degenerative component and a proliferation component at the same time [3]. The condition is benign in most cases, with minimal symptoms like foreign body sensation and burning.

Some studies considered Pterygium as a neoplastic process; they linked this tumor proliferation with p53 dysfunction and altered stem cell activity [4]. Progressive 
Pterygium growth passes to the cornea and impairs vision. At this point, surgical treatment is the standard gold method. Unfortunately, there is a recurrent rate of pathology that requires removal. Transposition of the conjunctival flap, conjunctival auto-transplantation, and amniotic membrane transplantation were common techniques to reduce the recurrence. Adjuvant drug therapy has been applied to reduce the risk of recurrence, like vascular endothelial growth factor inhibitors [5]. Conservative treatment is partially successful in non-fibrotic conditions [6].

Topoisomerase 1 is an important enzyme in DNA synthesis related to tumor progression [7]. Topoisomerase 1s are nuclear enzymes that release DNA rigidity allowing DNA replication. Topoisomerase 1 is a marker of cell proliferation and helps in the diagnosis of cancers. It is a target of anticancer therapy. This enzyme expression may explain the pathogenesis and the prognosis of proliferative disorders [8].

The current work will hopefully use immunohistochemistry to examine the two markers glutathione and topoisomerase 1 to explain the interaction between both degenerative and proliferative mechanisms occurring in the same disorder. Hopefully, it is suggested that immunohistochemistry can help in the prediction of the recurrence and possibly the mechanisms involved in this disorder.

\section{PATIENTS AND METHODS}

The current research work is a single-center retrospective study conducted at the Department of Ophthalmology, and the Department of Pathology, Mansoura University, Egypt, according to the tenets of the declaration of Helsinki. The article was accepted by the IRB of the faculty of Medicine, Mansoura University, code number R.20.01.728

The inclusion criteria were as follows: age 18 years or more, unilateral nasal primary or recurrent Pterygium, prominent growth, reported vascularization, uncontrollable irritation symptoms, and growth invasion of the corneal surface by about $2-4 \mathrm{~mm}$. While, the exclusion criteria were: pseudoPterygium, ocular surface disorders (as severe dry eye), eyelids infection or infection of the ocular surface, patients reported active extensive intraocular inflammatory reaction, patients with ocular hypertension or on glaucoma under medical control, patients with advanced, recurrent Pterygium that extends between the pupil and limbus at the time of the presentation, and combined other eye surgical history within the previous last six months (Tables 1-3).

Table 1. The relation between the types of Pterygium either primary or secondary (recurrent) and the gender.

\begin{tabular}{|c|c|c|c|c|c|}
\hline \multicolumn{3}{|c|}{ Gender } & \multicolumn{2}{|c|}{ Type of Pterygium } & \multirow{3}{*}{$\begin{array}{c}\text { Total } \\
9 \\
\end{array}$} \\
\hline & & & Primary & Secondary & \\
\hline \multirow{4}{*}{ Sex } & \multirow{2}{*}{ Female } & Count & 6 & 3 & \\
\hline & & $\%$ of Total & $22.2 \%$ & $11.1 \%$ & $33.3 \%$ \\
\hline & \multirow{2}{*}{ Male } & Count & 14 & 4 & 18 \\
\hline & & $\%$ of Total & $51.9 \%$ & $14.8 \%$ & $66.7 \%$ \\
\hline \multirow{2}{*}{\multicolumn{2}{|c|}{ Total }} & Count & 20 & 7 & 27 \\
\hline & & $\%$ of Total & $74.1 \%$ & $25.9 \%$ & $100.0 \%$ \\
\hline
\end{tabular}

- Results of immunohistochemical staining:
Table 2. Glutathione immune staining grading with primary\& secondary Pterygium and with gender.

\begin{tabular}{|c|c|c|c|c|}
\hline Primary & G0 & G1 & G2 & G3 \\
\hline Male (13) & 3 & 4 & 2 & 4 \\
\hline Female (7) & 1 & 2 & 2 & 2 \\
\hline Secondary & & & & \\
\hline Male (4) & 0 & 0 & 2 & 2 \\
\hline Female (3) & 0 & 0 & 0 & 3 \\
\hline
\end{tabular}

Table 3. Topoisomerase 1 immune staining grading with primary \& secondary Pterygium and with gender.

\begin{tabular}{|c|c|c|c|c|}
\hline Primary & G0 & G1 & G2 & G3 \\
\hline Male (13) & 13 & 0 & 0 & 0 \\
\hline Female (7) & 7 & 0 & 0 & 0 \\
\hline Secondary & & & & \\
\hline Male (4) & 2 & 0 & 2 & 0 \\
\hline Female (3) & 3 & 0 & 0 & 0 \\
\hline
\end{tabular}

\subsection{Surgical Technique}

All surgical maneuvers have been applied by one surgeon (AEB) using topical anesthesia $(0.5 \%$ propacaine $\mathrm{HCl}$ : Alcaine; Alcon Inc., Fort Worth, TX, USA) and subconjunctival anesthesia (lidocaine $10 \mathrm{mg} / \mathrm{ml}+$ epinephrine $0.0125 \mathrm{mg} / \mathrm{ml}$ ) during the period between October 2104 to March 2015.

As regarding primary Pterygium, the bare scleral technique was performed. After careful dissection, the surgeon excised the Pterygium head with a small part of its body. Furthermore, the underlying tenon tissue was removed from the cornea and the sclera using scissors. Remnant Pterygium tissue on the cornea was separated with a crescent knife. The bare sclera was evaluated with a caliper to leave $2 \mathrm{ml}$ from the limbus. It was essential to secure the conjunctive with $4-6$ separated $7 / 0$ vicryl sutures to the surrounding conjunctiva.

For secondary (recurrent) Pterygium, the conjunctiva was freed and settled (but not resect) back to the fornix to prevent conjunctival shortening or symblepharon. Blunt dissection was undertaken to cut the Pterygium head from the cornea, the epithelium of the Pterygium body from the subconjunctival fibrous tissue, and then the subconjunctival fibrous tissue from the sclera. The second step was sealing the gap between the recessed conjunctival edge and Tenon's capsule by applying a running 9-0 nylon suture to hopefully avoid recurrence.

To manage recurrent Pterygium conditions with limited conjunctival tissue in the caruncle due to the presence of significant conjunctival scarring, a small conjunctival autograft was completed to reconstruct better fornix. The medial rectus muscle was uncovered and hooked after a conjunctival recession, and the conjunctival cicatrix was freed to avoid the muscular injury. As regarding postoperative care, all candidates received an antibiotic eye drop $(0.3 \%$ Ofloxacin: Exocin; Allergan Inc.) four times a day for 1 week, and lubricant eye drop (Polyvinyl Alcohol and Povidone: Refresh single; Allergan Inc., Parsippany, NJ, USA) four times a day 
for 6 weeks. Corticosteroid eye drop ( $0.1 \%$ Fluorometholone) was added.

\subsection{Laboratory Methods}

Pterygium Sample Collection from each patient was sent to Pathology Department Laboratories, Faculty of Medicine, Mansoura University, Egypt in formalin solution 10\%. For more accuracy, the samples were labeled by serial ID numbers with full personal and clinical data.

\subsection{Sample Processing}

The samples were remolded in Paraffin blocks and categorized into two different groups: the Primary Pterygium group (20 samples) and recurrent Pterygium group (7 samples). The samples were fixed in formalin and subjected to $\mathrm{H} \& \mathrm{E}$ staining firstly, then immunohistochemistry for both reduced glutathione and topoisomerase I.

\subsection{Immunohistochemistry}

The samples were stained depending on the avidin-biotin technique. The tissue was heated to 95 degrees in the PT link of Dako for $30 \mathrm{~min}$ for antigen retrieval. 3\% hydrogen peroxide solution was loaded for $10 \mathrm{~min}$ to aiming to block endogenous peroxidase, then washing them in PBS. Then, an overnight incubation was done with antibody dilution of $1 / 150$ of mouse monoclonal anti-Glutathione $\mathrm{S}$ transferase (Cat. No. (4B6) ab170323, abcam). Anti-topoisomerase 1with dilution of $1 / 50$ (SC69-03) (NBP 2-67606, Novus) then washing in PBS. After that, a secondary antibody (1:1000; Invitrogen, Carlsbad, CA, USA) was added for $2 \mathrm{~h}$ at room temperature. Three washes with PBS were then applied, slides were mounted with a medium containing DAP. Hematoxylin was used to counter the stain. Absolute alcohol was added to clear the field. The positive control was kidney tissue for Glutathione and thyroid tissue for topoisomerase 1. Negative control slides were subjected to the same step, but no antibody was added.

\subsection{Immunohistochemistry Assessment}

\subsubsection{Percentage of Positive Cells}

- Positive staining: Brown staining of $\geq 5 \%$ of the total number of epithelial cells is considered positive for both glutathione (cytoplasmic) and topoisomerase 1 (nuclear).

- Negative staining: if brown cells represent less than 5\% of total epithelial cells.

- Mild positive (score 1): if brown stained cells represent $5-25 \%$

- Moderate positive (score 2): if brown stained cells represent $25-50 \%$

- Strong positive (score 3): if brown stained cells represent $>50 \%$

\subsubsection{The Intensity of Staining}

- Weak positive (score 1): if the intensity of staining is weak (light brown)

- Moderate positive (score 2): if the intensity of staining is a moderate degree.

- Strong positive (score 3): if the intensity of staining is very dark brown

\subsubsection{Total Scoring}

Total scoring $=$ score of percentage of positive cells + score of the intensity of staining.

Grade 0 (negative) for score 0 or 1

Grade 1 positive for score 2

Grade 2 positive for score 3 or 4

Grade 3 positive for score 5 or 6

Statistics: the study was analyzed by SPSS package version for descriptive statistics.

\section{RESULTS}

About $74 \%$ of the total cases were primary Pterygium; more than $51 \%$ of them were males. Also, males dominated the secondary Pterygium of about $67 \%$. Males were dominating the number of Pterygium cases in either primary or secondary Pterygium. The age of patients in the current study ranged from 18 to 55 years.

\section{- Results of Hematoxylin and Eosin staining:}

Fig. (1) showed The $\mathrm{H}$ and $\mathrm{E}$ of both primary and secondary Pterygium. The slides demonstrated epithelial hyperplasia and atypia in the primary forms. The reaction has been more intense in the secondary Pterygium demonstrating ulcerations and more dysplastic activity of the epithelium.

The epithelial changes included epithelial atypia in $40 \%$ of cases, mostly reactive atypia mild to a moderate degree equally distributed in primary and secondary Pterygium. Severe dysplasia (2cases) was observed in secondary Pterygium. Epithelial hyperplasia was observed in all cases of primary and secondary Pterygium. Goblet cell hyperplasia was observed in $30 \%$ of primary Pterygium cases and $50 \%$ of secondary cases. Prominent epithelial pigmentation was present in $30 \%$ of cases. Mild epithelial lymphocytic exocytosis was observed in $65 \%$ of cases; the moderate form was observed in $35 \%$ of cases, mostly secondary (Fig. 1).

Stromal inflammation had a perivascular pattern in $70 \%$ of cases. $30 \%$ of cases showed no stromal inflammation. Stromal solar elastosis was evident in all cases. Evident stromal vascularity was observed in $50 \%$ of cases with higher incidence with secondary cases (Fig. 2).

It was recorded that $85 \%$ of the cases were positively stained with reduced glutathione. The remaining 4 cases (15\%) of negative cases were primary and 3 of them were males. Most (75\%) of primary cases of Pterygium were positive for reduced glutathione. More than $60 \%$ of them have a high grade of staining; indicating the role of oxidative stress leading to degeneration in the pathogenesis of the disease.

All secondary causes of Pterygium were positive for reduced glutathione; all of them expressed high-grade staining for reduced glutathione representing more release of oxidative stress factors with secondary cases than primary ones. 
All cases of Pterygium were negative for topoisomerase 1except two cases $(7.4 \%)$ were secondary cases with moderate grading of positivity. However, all cases showed internal control stem cells positivity scattered focal between the basal cell layers of covering epithelium.

Fig. (3) showed the immunostained slides for both reduced glutathione and topoisomerase 1for both primary and secondary Pterygium. Primary Pterygium slides were mildly positive for reduced glutathione and only stem cells got positive for topoisomerase 1alpha. On the other hand, secondary Pterygium expressed more glutathione stain and mild positive topoisomerase 1 stain not only for stem cells but also for the superficial prickle cells in the secondary Pterygium
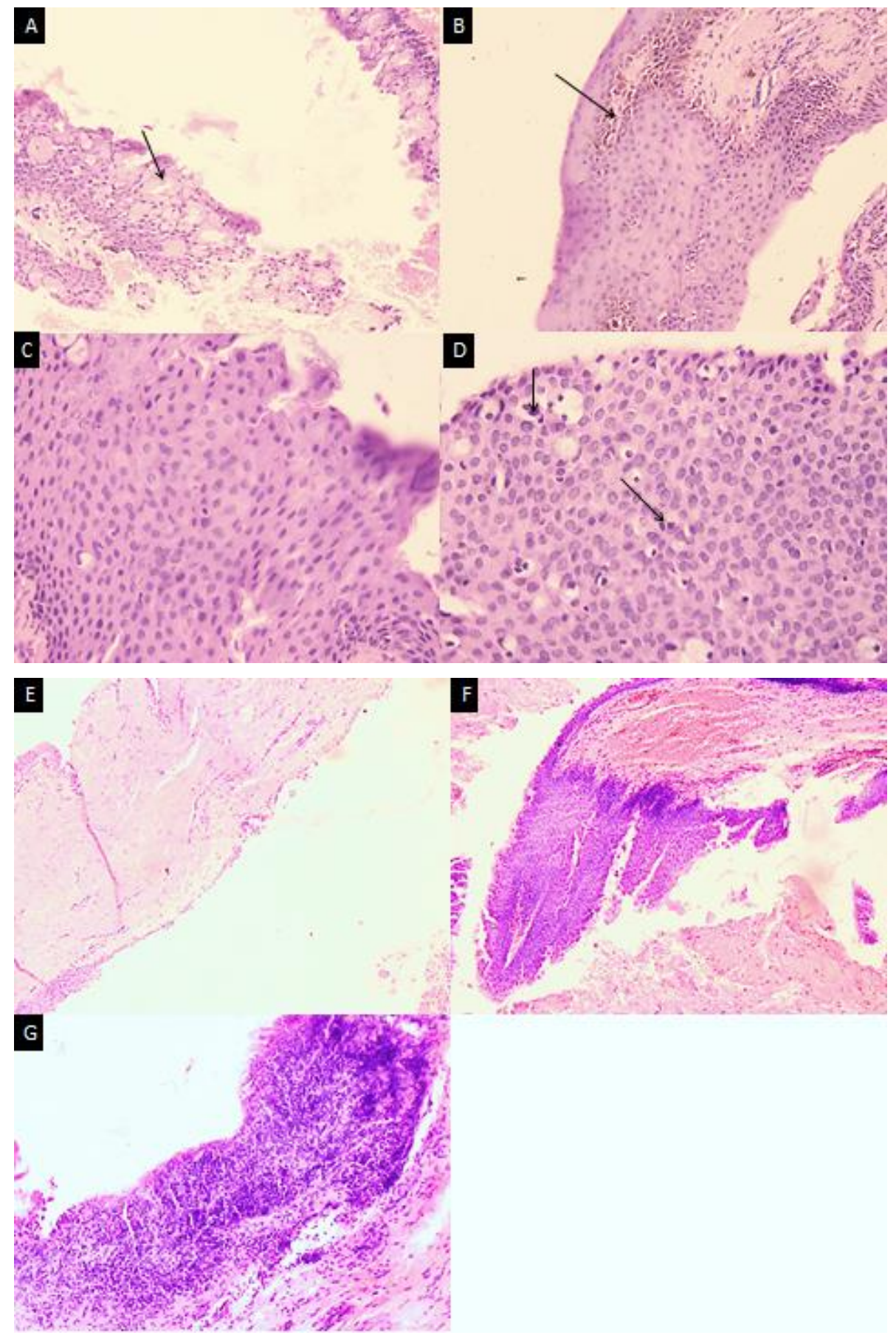

Fig. (1). Epithelial changes seen in Pterygium: A) goblet cell hyperplasia, seen more with secondary Pterygium. hematoxylin and eosin (h and e) stain, x200. B) Epithelial pigmentation, h and e, x200 C) Epithelial hyperplasia with reactive epithelial atypia, h, and e, x400 D) Epithelial lymphocytic exocytosis, h, and e, x400 E) Epithelial ulceration was seen more with secondary Pterygium, h and e, x100 F) Moderately dysplastic epithelium was seen in primary Pterygium, h, and e, x100 G) sever dysplastic epithelium was seen in secondary Pterygium, h, and e, x200. 


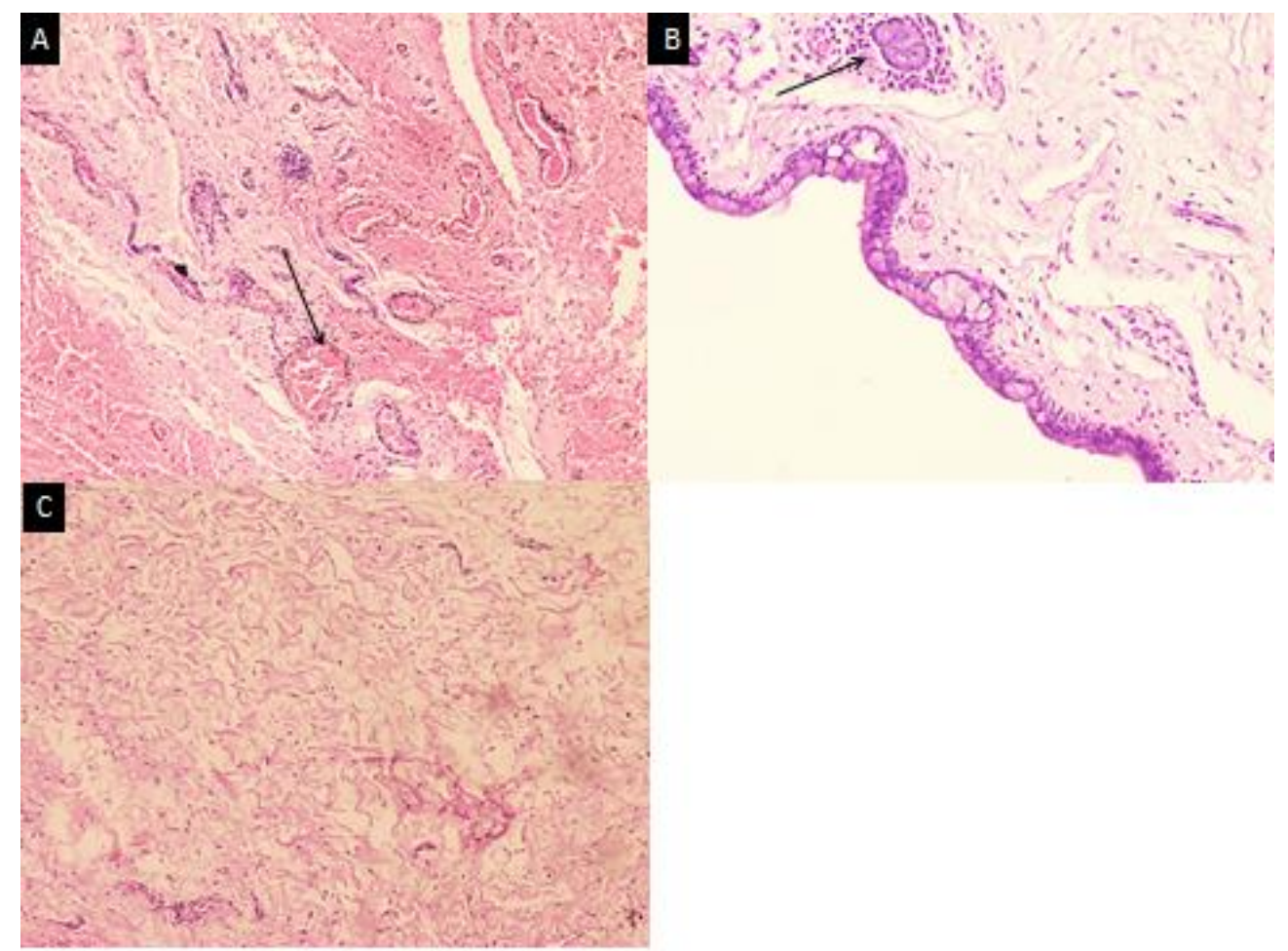

Fig. (2). Stromal changes in Pterygium: A) vascular proliferation and angiogenesis with interstitial hemorrhage seen in secondary Pterygium, h and e, x200 B) peri-appendageal lymphocytic infiltration, $h$ and e, x200. C) Solar elastosis, $h$ and e, x100.

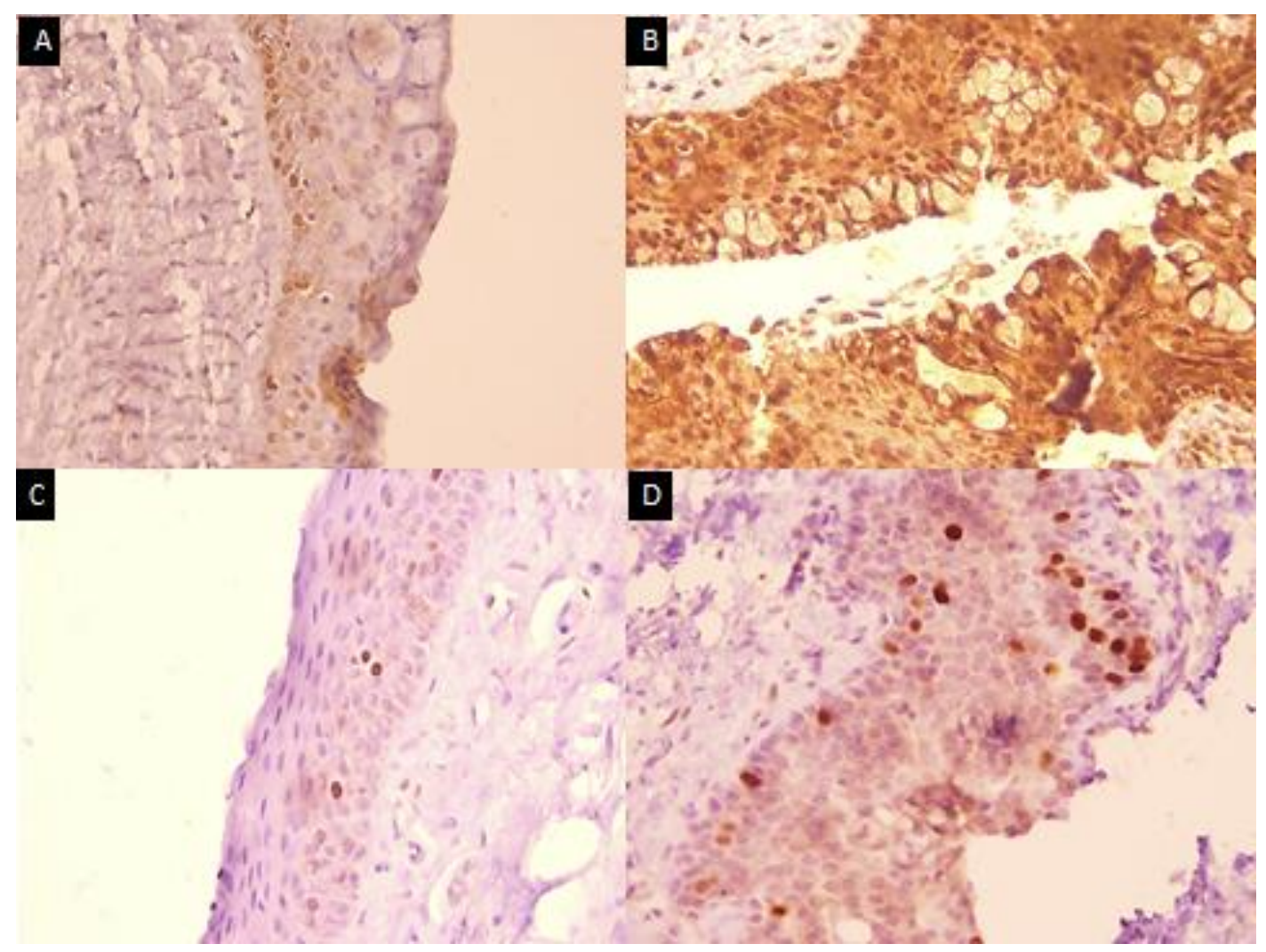

Fig. (3). Immunohistochemical staining with Reduced-glutathione and Topoisomerase1: A) mild positivity (+2) for glutathione seen in primary Pterygium x 40 B) strong positivity ( +3 ) for glutathione seen in secondary Pterygium x400 C) negative for Topoisomerase seen in primary Pterygium (internal control positive for stem cells seen as focal basal positivity)x400 D) mild focal positivity at superficial prickle cell layer seen in secondary Pterygium $\times 400$. 


\section{DISCUSSION}

The current study examined both primary and secondary Pterygium immunohistochemistry staining with both reduced glutathione and Topoisomerase 1. The reduced glutathione immune stain reflected the redox status and the degenerative component of the disease [7, 9]. Lymphangiogenesis has been proposed as a mechanism of Pterygium [10]. There are strong risk factors of oxidative inflammation, viral causes, and oncogenic activation in the contribution of the development of the double hybrid pathology Pterygium. Studies recommended the human papillomavirus as a candidate for being a causing virus of Pterygium [11].

The reduced glutathione immune stain showed a strong reaction in most of the cases with marked stain percentage and intensity in the secondary forms. Other studies supported the idea that oxidative stress induced by ultraviolet rays is part of the pathogenesis of Pterygium. They found a positive defensive reaction of malondialdehyde (MDA) levels, superoxide dismutase (SOD), and catalase (CAT) activities in the conjunctival samples taken from patients suffering from Pterygium and cataract as an aging process $[12,13]$. A very close work showed that a very similar glutathione immune staining score in both intensity and spread. The author attributed the positive glutathione results to the defensive antioxidant capacity against free radicals generated by the sun ray's exposure [14].

Ultraviolet rays have dual degenerative/ proliferative effects that may promote Pterygium. These rays stimulate the VEGF (Vascular Endothelial Growth Factor), promoting lymphangiogenesis. Experimental inhibition of the VEGF prevents the lymphatic reaction [15]. Corneal herpes viral infection may be a contributing factor to the development of lymphangiogenesis as well as ultraviolet factors [16].

The current study noticed that Topoisomerase 1stained the stem cell of the tissue samples reflecting a possible aberrant stem activity. This focal activity may be a marker for progenitor activity to explain the proliferative component of the Pterygium. Topoisomerase 1 may be a clue to the mechanism of recurrence or possibly a prognostic factor. Experimental work on human leukemia cell lines showed increased topoisomerase lin many cancers like colorectal, ovarian, cervical, prostatic, and even lymphomas [17]. Another important data is that topoisomerase lover expression was correlated with the bad prognosis of colorectal metastasis [18]. The possible common pathogenesis in both Pterygium and colorectal carcinoma can be explained by K-ras activation that sun rays can mutate. The possible common interaction between both K-ras and topoisomerase alpha may be target pathways for both diseases and even may predict their outcomes [19].

Those slides showed positive staining for Topoisomerases and, at the same time, reduced glutathione are mainly respecting the pattern of secondary behavior. The current study proposes that a panel of immunohistochemistry staining of reduced glutathione, Topoisomerase, and possibly others like p53 or the vascular endothelial growth factor in combination could be a good method to predict the prognosis of Pterygium. Limitations of this study include the small number of cases and the limited number of immune panels like p53 and possibly others like aging markers.

\section{CONCLUSION}

Pterygium is a wide world multifactorial disorder. The degenerative component is strongly related to oxidative stress conditions detected by immune stain with glutathione, while the proliferative component can be explained by stem cell activity demonstrated by focal topoisomerase 1 activity. A panel of immunohistochemistry may be a good tool to predict the recurrence rate.

\section{ETHICS APPROVAL AND CONSENT TO PARTICIPATE}

This study was approved by the Institutional Review Board of the Faculty of Medicine, Mansoura University, Mansoura, Egypt with code number R.20.01.728.

\section{HUMAN AND ANIMAL RIGHTS}

No animals were used in this research. All human research procedures were followed in accordance with the ethical standards of the committee responsible for human experimentation (institutional and national), and with the Helsinki Declaration of 1975, as revised in 2013.

\section{CONSENT FOR PUBLICATION}

Informed consent was obtained from all the participants.

\section{AVAILABILITY OF DATA AND MATERIALS}

Not applicable.

\section{FUNDING}

None.

\section{CONFLICT OF INTEREST}

The authors declare no conflict of interest, financial or otherwise.

\section{ACKNOWLEDGEMENTS}

We are thankful to the technician Ahmed Hashish of the pathology department of Mansoura University.

\section{REFERENCES}

[1] Malozhen SA, Trufanov SV, Krakhmaleva DA. Pterigium: étiologiia, patogenez, lechenie. Vestn Oftalmol 2017; 133(5): 76-83. [Pterygium: etiology, pathogenesis, treatment].

[http://dx.doi.org/10.17116/oftalma2017133576-83] [PMID: 29165417]

[2] Rezvan F, Khabazkhoob M, Hooshmand E, Yekta A, Saatchi M, Hashemi H. Prevalence and risk factors of pterygium: a systematic review and meta-analysis. Surv Ophthalmol 2018; 63(5): 719-35. [http://dx.doi.org/10.1016/j.survophthal.2018.03.001] [PMID: 29551597]

[3] Saw SM, Tan D. Pterygium: prevalence, demography and risk factors Ophthalmic Epidemiol 1999; 6(3): 219-28. [http://dx.doi.org/10.1076/opep.6.3.219.1504] [PMID: 10487976]

[4] Rong SS, Peng Y, Liang YB, Cao D, Jhanji V. Does cigarette smoking alter the risk of pterygium? A systematic review and meta-analysis. Invest Ophthalmol Vis Sci 2014; 55(10): 6235-43.

[http://dx.doi.org/10.1167/iovs.14-15046] [PMID: 25190665]

[5] Golu T, Mogoantă L, Streba CT, et al. Pterygium: histological and 
immunohistochemical aspects. Rom J Morphol Embryol 2011; 52(1): 153-8

[PMID: 21424047]

[6] Reda AM, Shaaban YMM, Saad El-Din SA. Histopathological parameters in pterygia and significant clinical correlations. J Ophthalmic Vis Res 2018; 13(2): 110-8.

[http://dx.doi.org/10.4103/jovr.jovr_31_17] [PMID: 29719637]

[7] Armand M, Besson C, Hermine O, Davi F. Hepatitis C virus Associated marginal zone lymphoma. Best Pract Res Clin Haematol 2017; 30(1-2): 41-9.

[http://dx.doi.org/10.1016/j.beha.2017.02.001] [PMID: 28288715]

[8] Perng DS, Tsai YH, Cherng J, et al. Discovery of a novel anticancer agent with both anti-topoisomerase I and II activities in hepatocellular carcinoma SK-Hep-1 cells in vitro and in vivo: Cinnamomum verum component 2-methoxycinnamaldehyde. Drug Des Devel Ther 2016; 10: $141-53$.

[http://dx.doi.org/10.2147/DDDT.S93599] [PMID: 26792981]

[9] Wanzeler ACV, Barbosa IAF, Duarte B, et al. Mechanisms and biomarker candidates in pterygium development. Arq Bras Oftalmol 2019; 82(6): 528-36. [PMID: 31576927]

[10] Uçakhan OO, Kanpolat A, Elgün S, Durak I. The role of oxidative mechanisms in the etiopathogenesis of pterygium: a preliminary study. Ophthalmologica 2009; 223(1): 41-6.

[http://dx.doi.org/10.1159/000167020] [PMID: 18987486]

[11] Balci M, Sahin S, Mutlu FM, Yağci R, Karanci P, Yildiz M. Investigation of oxidative stress in pterygium tissue. Mol Vis 2011; 17: 443-7.

[PMID: 21321673]

[12] Kajiya K, Hirakawa S, Detmar M. Vascular endothelial growth factorA mediates ultraviolet B-induced impairment of lymphatic vessel function. Am J Pathol 2006; 169(4): 1496-503. [http://dx.doi.org/10.2353/ajpath.2006.060197] [PMID: 17003502]

[13] Gurung HR, Carr MM, Carr DJ. Cornea lymphatics drive the CD8 $8^{+}$Tcell response to herpes simplex virus-1. Immunol Cell Biol 2017; 95(1): 87-98.

[http://dx.doi.org/10.1038/icb.2016.80] [PMID: 27577867]

[14] Delgado JL, Hsieh CM, Chan NL, Hiasa H. Topoisomerases as anticancer targets. Biochem J 2018; 475(2): 373-98.

[http://dx.doi.org/10.1042/BCJ20160583] [PMID: 29363591]

[15] Li M, Liu Y. Topoisomerase i in human disease pathogenesis and treatments. Genomics Proteomics Bioinformatics 2016; 14(3): 166-71. [http://dx.doi.org/10.1016/j.gpb.2016.02.004] [PMID: 27181710]

[16] Shaojun C, Li H, Haixin H, Guisheng L. Expression of Topoisomerase 1 and carboxylesterase 2 correlates with irinotecan treatment response in metastatic colorectal cancer. Cancer Biol Ther 2018; 19(3): 153-9. [http://dx.doi.org/10.1080/15384047.2017.1414754]

[PMID 29261002]

[17] Husain I, Mohler JL, Seigler HF, Besterman JM. Elevation of topoisomerase I messenger RNA, protein, and catalytic activity in human tumors: demonstration of tumor-type specificity and implications for cancer chemotherapy. Cancer Res 1994; 54(2): 539-46.

[PMID: 8275492]

[18] Ozturk BT, Yıldırım MS, Zamani A, Bozkurt B. K-ras oncogene mutation in pterygium. Eye (Lond) 2017; 31(3): 491-8.

[http://dx.doi.org/10.1038/eye.2016.254] [PMID: 27834959]

[19] Karadag R, Bayram N, Oguztuzun S, et al. Investigation of glutathione $\mathrm{s}$-transferase isoenzyme protein expression in patients with pterygium. Cornea 2016; 35(8): 1089-92.

[http://dx.doi.org/10.1097/ICO.0000000000000827] [PMID: 27032026]

(C) 2021 Ghorab et al.

This is an open access article distributed under the terms of the Creative Commons Attribution 4.0 International Public License (CC-BY 4.0), a copy of which is available at: https://creativecommons.org/licenses/by/4.0/legalcode. This license permits unrestricted use, distribution, and reproduction in any medium, provided the original author and source are credited. 